\title{
Some Philosophical Problems of Studying Complex Systems in the Universe
}

\author{
Alexei V. Nesteruk ${ }^{1}$, Aleksandr V. Soldatov ${ }^{凶}$ \\ ${ }^{1}$ University of Portsmouth, Portsmouth, UK \\ ${ }^{2}$ State Marine Technical University, St Petersburg, Russia \\ \soldatov2012@yandex.ru
}

\begin{abstract}
Introduction. The paper deals with the philosophical problems of functioning of the most complex phenomena in the universe: creation of the universe, emergence of life and appearance of consciousness. The scientific timeliness of the research is determined by that unceasing interest to the origin of the universe and life in it. The most difficult problem is the origin of intelligence in the universe which is confirmed through the ongoing research in the SETI program. The scientific novelty of research is that the authors link three fundamental problems relates to the origins of complexity in the universe in a single intellectual cluster.
\end{abstract}

Methodology and sources. The analysis is based on the issues in modern cosmology, astrobiology and anthropology treated in the context of complex systems and their radical sensitivity to the uncontrolled initial conditions. In particular, one implies the so called "fine-tuning" of the cosmological parameters necessary for the origin of life on the planet Earth. The hypothetical deviation of the numerical values of such parameters by, let say some per cents, would exclude the development of the biological systems. However the sphere of the necessary conditions for these parameters does not guarantee the fulfillment of the sufficient conditions for creation complexity and a possibility of life. Such conditions are not determined by the physical and biological context and make inevitable an appeal for their interpretation to philosophical ideas. The methodological foundation of this research is based in finding the boundaries of efficiency of the necessary conditions for emergence of complexity and attempts to provide in some cases an interpretation of the possible sufficient conditions.

Results and discussion. It is shown that it is impossible to account on scientific grounds for the original conditions which launched creation of the universe, emergence of life and appearance of consciousness. Scientifically, one can formulate the necessary conditions for existence of life in the universe and hence the embodied consciousness, however it is beyond the reach of science to account for the sufficient conditions. One simple model of origin of life illustrating the dependence of its phenomenon on the uncontrolled sufficient conditions is proposed on the grounds of analogy with Bernard's instability in complex systems.

If one identifies such phenomena as existence of the universe, biological and intelligent life with the behavior in super-complex material systems, there still remains a fundamental problem in unpredictability and contingency of those "initial" conditions which predetermined the factual outcomes in evolution of these complex systems. In other words science faces a fundamental limitedness in describing the sufficient conditions (sufficient reason) for those forms of complexity in nature with which this article deals. 
Conclusion. A scientific description of the most complex phenomena such as the universe as a whole, biological and intelligent life demonstrate its limited scope as regards the sufficient conditions for their happening. In this sense an exhaustive understanding of these phenomena becomes fundamentally impossible, showing that science functions in the conditions of the positive uncertainty.

Key words: complexity, consciousness, humanity, nature, persons, philosophy, scientific method, universe.

For citation: Nesteruk A. V., Soldatov A. V. Some Philosophical Problems of Studying Complex Systems in the Universe. DISCOURSE. 2019, vol. 6, no. 3, pp. 21-34. DOI: 10.32603/2412-8562-20206-3-21-34

Conflict of interest. No conflicts of interest related to this publication were reported. Received 07.04.2020; adopted after review 10.03.2020; published online 25.06.2020

\title{
Некоторые философские проблемы изучения сложнообразованных систем во вселенной
}

\author{
A. В. Нестерук' ${ }^{1}$ А. В. Солдатов ${ }^{2 凶}$ \\ ${ }^{1}$ Университет Портсмута, Портсмут, Великобритания \\ ${ }^{2}$ Санкт-Петербургский морской технический университет, Санкт-Петербург, Россия

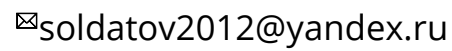

Введение. В статье рассматриваются философские проблемы при анализе наиболее сложных явлений во вселенной: происхождение вселенной в целом, возникновение жизни на планете и появление разума. Научная актуальность проводимого исследования определяется неослабеваемым интересом к проблемам происхождения вселенной и жизни в ней. В частности связью между параметрами крупномасштабной вселенной и локальными условиями возможности возникновения жизни во вселенной. Наиболее трудной проблемой является возникновение разумной жизни во вселенной. Это подтверждается неослабеваемым интересом к проблеме SETI. Научная новизна исследования состоит в том, что авторы связывают в один интеллектуальный кластер три фундаментальные проблемы, связанные с возникновением сложности во вселенной

Методология и источники. Исследование базируется на анализе современных данных из космологии, астробиологии и антропологии в контексте представлений о сложных системах и предельной чувствительности режимов сложности по отношению к неконтролируемым начальным условиям. В частности речь идет о «точной настройке» космологических параметров для тоого, чтобы выполнялись необходимые условия для возможности образования жизни на Земле. Отклонение этих параметров на несколько процентов ислючало бы образование сложных биологических систем. Однако сфера необходимых условий таких параметров не гарантирует выполнения достаточных условий образования сложных систем и возможности жизни. Такие условия не детерминированы физикой или биологией систем и предполагают для их интерпретации обращение к философским представлениям. Методолоиической основой исследования как раз и является выявление границ действия необходимых условий образования сложности и попыток дать в ряде случаев интерпретацию возможных достаточных условий. 
Результаты и обсуждение. Показана принципиальная невозможность предсказания или контроля исходных условий, которые положены в основу динамики сложных систем и приведших к образованию наблюдаемой вселенной, возникновению жизни на Земле и появлению сознания. Научные методы позволяют сформулировать только необходимые условия для существования биологической жизни и воплощенного сознания во вселенной. Однако эти методы оказываются неприменимыми для раскрытия смысла достаточных условий. На основе аналогии возникновения жизни с так называемой нестабильностью Бернара в сложных физических системах предложена простая иллюстрация чувствительности результата возможного развития сложной системы к неконтролируемым начальным условиям.

Если исходить из того, что к таким явлениям, как вселенная в целом, биологическая и разумная жизнь могут быть применены теории возникновения сложности, то попрежнему остается фундаментальная проблема непредсказуемости и онтологической случайности тех «начальных» условий, которые детерминировали фактический результат эволюции сложных систем. Другими словами, существует принципиальный предел на возможность описания с помощью научных методов достаточных условий (достаточного основания) возникновения сложных систем высшего порядка, таких как вселенная и разумная биологическая жизнь.

Заключение. Научное описание наиболее сложных систем, таких как вселенная в целом, биологическая и разумная жизнь показывает свою собственную ограниченность в отношении понимания достаточных условий, лежащих в основании результатов развития таких систем. Исчерпывающее понимание таких явлений становится недостижимым, показывая, что науки о происхождении сложности функционируют в условиях так называемой позитивной неопределенности.

Ключевые слова: вселенная, личность, научный метод, сложность, сознание, феноменология, философия, человек, природа.

Для цитирования: Нестерук А. В., Солдатов А. В. Некоторые философские проблемы изучения сложнообразованных систем во вселенной // ДИСКУРС. 2020. Т. 6, №3. С. 21-34. DOI: $10.32603 / 2412-8562-2020-6-3-21-34$

Конфликт интересов. О конфликте интересов, связанном с данной публикацией, не сообщалось.

Поступила 07.04.2020; принята после рецензирования 10.03.2020; опубликована онлайн 25.06.2020

Introduction. In spite of the seeming efficiency of modern natural, human and social sciences describing, explicating and interpreting all levels of the world's being (observable universe and our planet emerging out of the physical evolution of the cosmos, extremely complex biological evolution as well as unpredictable history and sociology of the human society), there remain three fundamental problems which are in the foundation of these sciences but not clarified by them. One implies that the condition of functioning of the human society which aspires towards survival on this planet and an adaptation to the external world through knowledge of it, improvement and simplification of the living conditions, achievements of some spiritual goals, are all implicitly grounded in basic empirical factors which predetermine the very possibility of functioning of humanity and its knowledge of the world. These factors are those "inaugural events" which endow the world and humanity by future. This is the reason why these events are problematic for being scientifically represented: all of them do lie in the foundation of the possibility of the scientific process as a modus of the human activity, but as such they escape the conditions of their scientific representation. 
Methodology and sources. If one adopts a natural philosophical attitude, that is considers these problems as corresponding to the objective uncertainty of the underlying phenomena, they can be described in the natural logical order:

1) origin of the universe.

2) emergence of life on Earth.

3) appearance of consciousness of Homo Sapiens.

Let us consider them in this order

1. Cosmology describes history of the universe by recreating it in an inverse temporal order from the present to its remote past. The laws of physics make it possible to produce a scenario of the universe's development from some initial state (Big Bang) where all possible existing forms of matter have been united in an undifferentiated state having from the physical point of view pathological (numerically infinite) characteristics. There are many models of the evolution of the universe which lead to the idea of the "beginning" of the world. However, all of them are based on a premise that there pre-existed some elementary ingredients of physical reality (for example, space, field, vacuum etc.) which were necessary for the description of the universe. However, the contingent facticity of these ingredients cannot be subjected to any physical description. The physical sciences can function only in the conditions when physical reality as such is already given. The question of origin of physical matter and space is a philosophical question, or event a theological one. The parameters of the initial condition of the universe as being determined through the backward extrapolation of the observable parameters of the universe at present turn out to be specific and concrete numerical constants whose quantitative facticity cannot be defined on the grounds of any underlying physics. Yet, all physical laws established in the terrestrial context function in the conditions of he contingent facticity of these constants. An example is the age of the universe (13.7-13.8 billion years) whose numerical contingency cannot be elucidated from within the physical if this universe. One cannot transcend the visible universe in order to establish some "trans-law" whose outcome could predict the age of the universe as 13.7 billion years. The contingency of the physical constants, the age of the universe and he initial conditions for its dynamics point to the radical contingency of the universe in a philosophical sense. This observation can be formulated in the following way: in spite of the fact that physics and cosmology can formulate the conditions of the factual existence of the visible universe, describing them in terms of observable constants, the very origination of the universe with such constants is not guaranteed by any laws on "this side of the universe", because neither the origin nor the sense of the initial state of the universe are clarified by reliable and verified physics (despite a variety of theoretical speculations of that which could "happen" before the Big Bang).

If one assumes, as it is done on theories of multiverse, that our universe with its unique initial condition arises from some ensemble of potential universes with an infinite variety of possible initial conditions then the apriori probability of such an origination, that is fixing the initial conditions pertaining to our universe, would be zero: $P_{\text {apriori }}=1 / \infty=0$. This probability entails an infinite informational uncertainty of appearance of our universe which is expressed through the informational entropy $\mathrm{I}_{\text {apriori }}=-\mathrm{P}_{\text {apriori }} \ln \mathrm{P}_{\text {apriori }}=\infty$. This means, that, saying metaphorically, in order to "choose" our universe from an infinite ensemble, one must possess infinite information. If one now estimates the posterior probability of our universe as $\mathrm{P}_{\text {posterior }}=$ 
$=1$, one concludes that there is no informational uncertainty anymore: $\mathrm{I}_{\text {posterior }}=\mathrm{P}_{\text {posterior }} \ln$ $\mathrm{P}_{\text {posterior }}=0$. Then it is not difficult to see that the transition from an infinite ensemble of the universe to the specific and particular our universe would require infinite amount of information from that "agency" which would effect such a transition $\Delta \mathrm{I}=\left|\mathrm{I}_{\text {posterior }}-\mathrm{I}_{\text {apriori }}\right|=\infty$. If one would treat this simple model as an epistemological exercise then it is obvious that man cannot possess infinite information and thus to understand the sufficient conditions of the origin of our universe. If one treats this transition from the ensemble of the universes to our universe as a physical one, a problem of energy costs arises. Since the production of a bit of information requires energy, it is unclear where from the physical mechanism of the transition arises if it requires infinite energy. This simple model explicated in a different way the unknowability of the initial condition of the universe and its radical contingency.

Now, leaving aside a question of the origin of the universe, accepting a principal difficulty in formulating the initial conditions of the universe and thus transferring it to a sphere of metaphysical speculations, let us concentrate on the next problem, namely of origin of life in the universe.

2. Now let us look at the phenomenon of human life from a cosmological perspective. We to start with a simple observation that the phenomenon of man, if it is seen from the point of view of the place and age it occupies in the overall history of the universe represents a tiny island in the vast ocean of physical being. According to modern cosmology, the universe is old and large. Its estimated age $T \simeq 13.8$ billion years, and its maximal observable size, corresponding to the distance which can be travelled by light during this $T$, is equal to $R_{U} \simeq 10^{28} \mathrm{~cm}$. If we accept that the hominids appeared on the planet Earth approximately 1 million years ago it is not difficult to estimate, in relative units, that the amount of time which human life exists in the universe $\Delta T$ with respect to the age of the universe $T$ is $1 / 10^{4}$ at the very end of the universe's evolution. As to the relative space, occupied in the universe by humankind (we mean the planet Earth with a radius $R_{E} \simeq 10^{9} \mathrm{~cm}$ ), the ratio will be even more impressive: $R_{E} / R_{U} \simeq 10^{-19}$ (the volume occupied by humans on the Earth will be $\simeq 10^{-57}$ of the volume of the observable universe). It is important to realize that the universe, being old and large, was unsuitable for the existence of human life most of the time and is probably unsuitable for life in most of its space (refusing any speculations about the extraterrestrial intelligent life). This brings us to the conclusion that the universe, understood as overall space-time, is effectively empty and dead in terms of life with only one exception, that is the life on the planet Earth.

One can easily illustrate this point by appealing to an anthropic argument which makes a link between the global physical conditions in the universe and the fact of existence of life on planet Earth. It is obvious that life could not exist in the past of the universe because it was hot. The stability of atoms is a fundamental condition for existence of all possible biological forms of life. It is known from atomic physics that in order to destroy atoms it is enough to expose atoms to external electromagnetic radiation, i.e. to highly energetic photons, whose energy is greater than the binding energy $E_{H}$. This implies that since all atomic structures are embedded in the external cosmological background, filled in with the so called inter-galactic gas (IGG) and the microwave relict background radiation (MBR), the energy of particles in IGG and MBR must be 
less than $E_{H}$. If we express this condition in terms of the effective temperature of particles and photons, using the connection between energy and temperature $E=k T$ ( $k$ is Boltzmann's constant) we can state that

$$
\mathrm{T}_{\mathrm{MBR}}[\simeq 3 \mathrm{~K}]<\mathrm{T}_{\mathrm{IGG}}[\simeq 100 \mathrm{~K}]<\mathrm{T}_{\mathrm{H}}\left[\simeq 10^{4} \mathrm{~K}\right]
$$

This inequality is satisfied at present age of the universe. In the past of the universe, however, this inequality would not hold, because, for example of the fact that the $T_{M B R}$ is the function of the radius of the universe $a(T \simeq 1 / a)$ and it increases in the past when $a \rightarrow 0$. At some point $\mathrm{T}_{\mathrm{MBR}}$ exceeded $\mathrm{T}_{\mathrm{H}}$ and all atoms could not exist, so that no physico-biological form of life would be possible.

Certainly this simple observation is true if we assume that the constant of electromagnetic interaction does not change in time. It is interesting to find, however, that its particular numerical value is critical for the condition of the stability of atoms to hold. Indeed if we change, hypothetically, its value, let us say we decrease its value ten times, then the corresponding temperature $\mathrm{T}_{\mathrm{H}}$, will be comparable with $\mathrm{T}_{\mathrm{IGG}}$ and atoms can be potentially destroyed by the interactions with the particles from IGG. In a similar way if we decrease the same constant in one hundred times, the corresponding temperature of atoms will be less than the temperature of MBR, so that atoms could not exist in the cosmological background at all. These simple arguments remind us again about the so called fine tuning of fundamental physical constants and external cosmological parameters, which provide the sustenance of life in the universe.

What is important for us, however, is that the brute fact of the observable values of the physical constants and cosmological parameters allows us to conclude that the conditions for life, understood in this context only in physical and biological terms, did not exist in the universe forever, i.e. the universe was not always "anthropic". One can object to this affirmation by saying that the universe is an evolutionary complex, and that the emergence of life at a certain point of its evolution and in a given place, was conditioned by the previous history of the universe, and it is in this sense one could assert that the universe was anthropic from the very beginning i.e. its initial conditions evolved later on leading to a cosmic environment such that the necessary condition of the emergence of life were fulfilled. The fact that we put a stress here on the word "necessary" (conditions for life) reflects the weak point of any physical cosmology and even biology as unable to reflect reasonably on the nature of the sufficient conditions for life to emerge in the universe.

The difficulty which cosmology runs into if it attempts to justify the sufficient conditions for the emergence of life can be easily illustrated by referring to what is accepted by modern cosmology as fact that life (again understood in physical and biological terms), existing in the universe here and now, is destined to disappear from its surface because either of terrestrial physical or cosmological reasons. In the astrophysical context the upper bound on the existence of life on planet Earth follows from finite age of existence of the Sun $(\approx 5$ billion years from now), whose termination in the explosion will bring any life in the surrounding cosmos, including the Earth to extinction. Even if we disregard this local cosmic catastrophe and hypothetically assume that humankind could spread beyond the Solar system into outer cosmic space, we still have to face some global cosmological constraints on the duration of its existence, following from the theory, namely the eternal frost of the ever-expanding universe. In this case, 
some cosmologists tried to argue that there will be a possibility to extend the 'existence' of 'life' in the universe, by abandoning the human body, and adjusting the new form of life to an absolutely different environment. These hypotheses were based on a speculative assumption that life can be defined in terms of mechanisms producing information, so that the question of supporting life in the universe is a question of producing information with no ending. It is enough to remind one of the long-standing paper of F. Dyson on life in the cold and dark future of the universe, where he argued that civilizations can survive there by constantly reducing their rate of energy consumption and information processing [1]. Dyson's argument was that in spite of this the total amount of information produced in the universe may still be infinite, which would imply that the post-human 'civilization' could live forever in its subjective time [2].

In spite of the-apriori speculative nature of this proposal, which is doubtful first of all on purely anthropological grounds, for it definitely departs far from what is usually understood by humanity as the existence in body and soul, the physics of Dyson's model was revised recently with a very pessimistic conclusion that his scenario of existence forever is physically unachievable [3].

It is now important to stress that all forecasts for the upper bound of duration of conscious life in the universe assume tacitly that humankind intends to continue to exist and does not participate actively in reducing its chances of survival, avoiding intentionally the situation on the terrestrial scale, which could be called a "doom-day syndrome". The latter is usually associated with the global ecological crisis, nuclear holocaust, some lethal experiments with germ warfare, or experiment with high-energy physics which could lead to the destruction not only of our planet, but the whole universe [4]. It is the possibility of the termination of the Humankind-Event by conscious being themselves, when their activity threatens the natural roots of their existence, that points out that the sufficient conditions for the endurance of this Event are partially rooted in the sphere of thought of these beings, in the realm of value and ethics [5].

This brief reference to the future evolution of the universe and the conclusion about the inevitable termination of life in physical and biological terms leads us the assertion that the universe is essentially "anti-anthropic" in the future, in spite of the fact that its present state provides the necessary conditions for the existence of life. We can summarise our point in the following formula: "The universe is anthropic now. It was 'anti-anthropic' in the past and it will be 'anti-anthropic' in the future". This leads us naturally to assumption that the phenomenon of life in the universe, considered at this stage only with respect to its grounds in physics and biology is finite, as regards to time and space. And its is because of this that we talk about the phenomenon of man as Humankind-Event, i. e. as a physical event whose spatial scale is finite and whose duration, in spite of being extended in time, is still finite and tiny (if seen from the present) with respect to the age of the universe. This event is not exactly what is usually meant by an event in the physics of relativity, where an event is assumed to have no temporal extension, i. e. it is treated as an instant, the set of which forms space-time. What is important in using the word "event" as applied to the phenomenon of man, is that this event is not inherent in the cosmological background (there is no ultimate causal link between cosmology and anthropology); it depends on it, i. e. the phenomenon of life is conditioned by physics, but only in terms of the necessary conditions. This means that in order for the Humankind-Event to happen, i. e. to become a part of history different from the dynamics of the cosmological 
background, there must be present some non-natural factors, making the event contingent upon these factors. What are they? With no ambition to give a final answer to this question we hope at least discuss this problem in the following sections.

Results and discussion. In order to elucidate the meaning of the concept of HumankindEvent as contingent upon non-natural factors, in a cosmological context we should relate it to the series of ideas which are broadly called as Anthropic Cosmological Principle (we use an abbreviation AP).

The so called Weak AP (WAP) concentrates upon the privileged spatio-temporal location of intelligent observes in the evolutionary Universe: they find themselves at a rather specific site, and at a later stage of the history of the Universe; the physical parameters which are treated as fundamental constants are not arbitrary, but rather fine tuned with the conditions that carbon-based life form can evolve [2, p. 16]. The WAP emphasizes that there are some necessary conditions which make it possible for life to emerge and to continue its existence in the universe: the universe must be old (at least 10 billion years) and large in order to create the conditions for carbon-based life-forms to emerge. The positive feature of the WAP is that it does not claim too much, that is it does not demand any inherent causality between the cosmological evolution and the emergence of life. It does not say anything about the laws of physics themselves, or about the values of the fundamental physical constants. It accepts these values as given and then attempts to explain some features of the universe. The WAP just says that in order for the Humankind-Event to happen, there must be fulfilled some cosmological conditions. Making a stress on the necessary conditions the WAP does not, in fact, address the issue of what was the actual cause of the Humankind-Event. It is also clear that the WAP does not run into the discussion of the future of the universe; in other words it leaves the question of the indefinite continuation of life out of its scope.

Cosmology and physics while they try to put the conditions of the existence of humanity in a cosmological context, deal only with the natural dimension of the Humankind-Event, i. e. with the existence of humans as physico-biological bodies. Physics itself can hardly speculate at present on the nature of human consciousness or soul [6, p. 163]. In other words physics and cosmology can discuss the human phenomenon only from a perspective of its materiality, that is in terms of physics and biology, which can be communicated from one being to another and form a large uni-natural population. The personal dimension of human existence is out of the scope of physics and biology, based on it. Certainly the conscious nature of humans is tacitly present in all cosmological insights, because all of them are made by the intelligent human beings, so that any claim about the universe has sense only in the context of the human intelligence in the cosmos. But cosmology has no key to the explanation of this intelligence itself. The intelligence is not obviously inherent in the cosmological observations and theories, it can only be established through philosophical introspection.

The WAP affirms the natural conditions for the Humankind-Event, but it does not relate to the issue why this event has happened, i. e. why the existence of human beings understood as differentiated persons became possible. In other words why the Humankind-Event happened not just an element in the natural chain of impersonal and dispassionate interplay between chance and necessity. One sees then that the problem of the sufficient conditions for life to emerge and to continue to exist in the universe in cosmology correlates with the mystery of the personal existence of human beings in philosophy. The insufficiency of cosmology to clarify the riddle of intelligent 
life in the universe points towards the grounds of life, which transcend the cosmological context, making the Humankind-Event relational (or contingent) upon some event-like factors which make impossible to use scientific theories working in the phenomanlity of objects.

It follows from what we have just said that the issue of the necessary conditions of the intelligent life in the universe must not be separated from the issue of the sufficient conditions. The AP is logically incomplete if it tries to affirm something about the structure of the universe relying only on the natural aspects of human existence. It follows then that the genuine Anthropic Principle must be constituted of both scientific and philosophical insights which would open a route to the demonstration of the contingency of human existence in the universe and to a more intricate involvement of human beings in comprehending the grounds of intelligibility of the universe.

From what we have said it becomes clear that even the more speculative Strong AP in cosmology does not reach its goal of proclaiming that the whole structure of the universe is to be subordinated to the fact of the existence of intelligent life in the universe: "the universe must have those properties which allow life to develop within it at some stage in its history [2, p. 21]." An attempt which the SAP makes in subordinating the entire history of the universe to the requirement that life can emerge in this universe has a modest utility in cosmology [7, 8]; it raises, however, some problems of a philosophical kind. Indeed if the SAP refers only to the natural aspects of human existence, then it obviously does not address the issue of sufficient conditions for the existence of life in the universe, for even if the universe is physically 'designed' in order to contain biological life, it is still unknown what was a particular cause which led ultimately to the emergence of biological organisms and the universe adjusted to it. The problem of consciousness in biological organisms is not even addressed by this Strong AP. There is some contingent element in the whole story of the appearance of life in the universe, which is fundamentally unavoidable if one thinks about it in purely physical terms.

In order to illustrate the last thought, we want to employ a simple model of the emergence of complexity in physics in order to show that it is always accompanied by a fundamental uncertainty, which cannot be resolved on a physical level but requires one to appeal to some trans-physical (and non-predictable) factors. Our example is based on two assumptions. The first one is that the phenomenon of life from a physico-biological point of view is associated with the "manifestation of the attainment of a particular level of organised complexity in a physical system" [9, p. 19]. The second assumption is that for heuristic modelling of the emergence of the organised complexity (associated with existence of life) one can use any physical model of complex phenomena, which involves an interplay of the necessary and sufficient conditions for the complexity to emerge. Under these two assumptions we intend to demonstrate that the emergence of 'life', understood simply as a definite level of complexity in a physical system, requires one not only to satisfy the necessary conditions, serving as a background for complex phenomena, but also to realize that a particular outcome of these phenomena (one of those could be associated with the emergence of life), will be a-priori unpredictable and contingent upon factors, which are not conceivable by the physics which operates with the given complex phenomena.

The simplest example of complexity in a physical system is known as the Bernard instability in the heat convection in the liquid contained between two planes with different temperatures in the external gravitational field [10]. The Bernard instability is the transition from 
an initially uniform liquid to the state where this liquid becomes ordered in space, in terms of the so called Bernard cells, with a typical size $1 / 10^{\text {th }} \mathrm{cm}$, in which $10^{21}$ molecules experience a special type of correlation. The transition from the uniform liquid to the structured liquid can be compared with the transition from a physical state of the universe with no life to the state when life emerged. In the case of the Bernard phenomenon the transition from the uniform state to complex state depends upon satisfying some necessary conditions: the presence of the external gravitational field, and the presence of the difference in temperature on the upper and low planes $\Delta \mathrm{T}$. When this difference reaches some critical value $\Delta \mathrm{T}_{\mathrm{c}}$ one observes the transition from the uniform liquid to the liquid which is formed by cell-tubes. If we make an analogy between the external factors in the Bernard experiment with the external cosmological conditions which are necessary for emergence of life (such as the strength of the cosmological gravitational fields and, the temperature of the background radiation which decreases as the universe expands), then the necessary condition for the Bernard phenomenon to occur can be paralleled with some cosmological event, when the temperature of the background radiation dropped down to such a level when the stability of the constituents of the biological factors on planet Earth, has been achieved and life could emerge.

The most intriguing part of the Bernard experiment, however, consists in the fact that the phenomenon of complexity can be of two different types. The Bernard cell in a given place of the liquid can have either clockwise (right - R) or anticlockwise (left - L ) chirality so that the spatial structure of complexity, attained in a fixed point of the liquid (related to a position of a hypothetical observer) can be depicted as a sequel of cells with different order of chiralities, namely either A: ...RLRLRL.. or B:...LRLRLR.... The phenomenon is deterministic with respect to the external, necessary conditions, but it is impossible to predict what particular outcome (either A or B) will take place. This means that if one repeats the experiment, leading to the Bernard instability many times, one can only predict the probability $\mathrm{P}_{\mathrm{A}}=1 / 2$ that there will be an outcome $\mathrm{A}$ and the probability $\mathrm{P}_{\mathrm{B}}=1 / 2$ that there will be an outcome $\mathrm{B}$.

If we now make a hypothesis that the state A corresponds to such a level of complexity which leads to 'life', whereas the state B is 'infertile', then one can affirm that in spite of the deterministic external necessary conditions for complexity to emerge, the actual happening in the system, leading either to 'life' or to 'no life' is not in a causal relation to the necessary conditions. It is probabilistic in its nature and depends on factors, which are not described by physical theory. What is the actual cause of a spontaneous breakdown of symmetry between 'life' and 'no life' remains unclear. In other words the sufficient conditions which led to emergence of life are not explained.

By concluding our discussion of a simple physical model of the emergence of complexity (which can be interpreted in a reductionist way as the emergence of life), we must rearticulate two important achievements: 1) the sufficient conditions for actual emergence of life in the universe can not be part of physical theory; this indicates the presence of fundamental, unavoidable, contingency in cosmological theory; 2) the anthropic arguments deal only with the natural aspects of the Humankind-event, whose actual happening is contingent upon some nonnatural grounds. This brings us finally to the understanding that the mystery of the Humankindevent and the attempt of cosmology to enquire into it through anthropic arguments is linked with 
the mystery of the hypostatic existence of human beings. Cosmology as taken in its purely scientific realisation can pretend to reveal the fundamental contingency of human existence in its natural dimension upon some specific conditions which have been realised in the universe. It will be, however, extremely difficult for cosmology alone (with no support of philosophy) to reveal the ground of the universe and human beings in it. But this exactly means that cosmology should look for the presence of contingent necessity in its laws and facts about the existence of human beings in the universe, that is the necessity which by its display in the universe never acquires the features of sufficiency; for the sufficiency, if it were to be possible to reveal it in the display of the universe, by its logical constitution, would be an ultimate ground of contingent necessity in the world, which would correspond to the hidden design of the universe.

One can conclude thus that the human phenomenon in the universe, analysed in the context of the Anthropic Arguments in cosmology, is in its essence finite and contingent upon some ill understood factors which can only be guessed through an appeal to philosophy. It is in this sense that all assertions of the WAP can be interpreted as the indications of the fundamental contingency present in astrobiological reserach, open to further explanation, based on nonphysical assumptions.

It can sound tautologous that the very fact that physics can speculate about the universe and the place of man in it is based on the ability of humans to contemplate the universe and form a coherent picture of the world. This ability is associated with the intelligence which makes human beings fundamentally different from other forms of biological life. This fact, in spite of being tacitly present in the very foundation of science is disregarded as constitutive for modern knowledge. Human beings as intelligent observers and conscious agencies in the universe are downgraded to the level of passive observers, so that the presupposition of the observations themselves, that is human consciousness, is excluded from the subject matter of physics [7]. Here we have two notes: 1) such a vision of humanity's place in the universe is fundamentally incomplete (and can be easily elucidated by a simple example); 2) the appearance of consciousness cannot be accounted through the physical factors, so that, once again, its sufficient conditions refer us to the realm of non-scientific explanation.

In order to deal with 1), let analyze a typical diagram from popular scientific books, which depicts different objects in the universe, starting from atoms and finishing with galaxies, in terms of their spatial sizes or in terms of their masses The reader can find these diagrams in many books (see for example [11, p. 49, 53; 9, p. 20;12, p. 5]). The position of human beings in this diagram is seen as mediocre: its typical spatial size is $10^{12}$ times higher than atomic one and the place they occupy in space is $10^{-19}$ times less than the size of the visible universe. In spite of the fact that the existence of human beings depends on atoms and the size of the Universe (this is an anthropic reasoning) the position of human beings in the universe is insignificant. For every contemplative thinker, the internal inconsistency of such a purely physical view is hidden in the fact that human reason is encoded in such a diagram implicitly. All objects are integrated in a single logical chain, which is possible only because the human insight. Thus all objects in the chain of physical being are united by human reason in a single consciousness of the whole which is sustained from the "vertical" dimension of human intellect, which is linked to the natural conditions of man's existence but also to "non-natural" factors related to personal consciuousness. This idea can be illustrated by the diagram. 


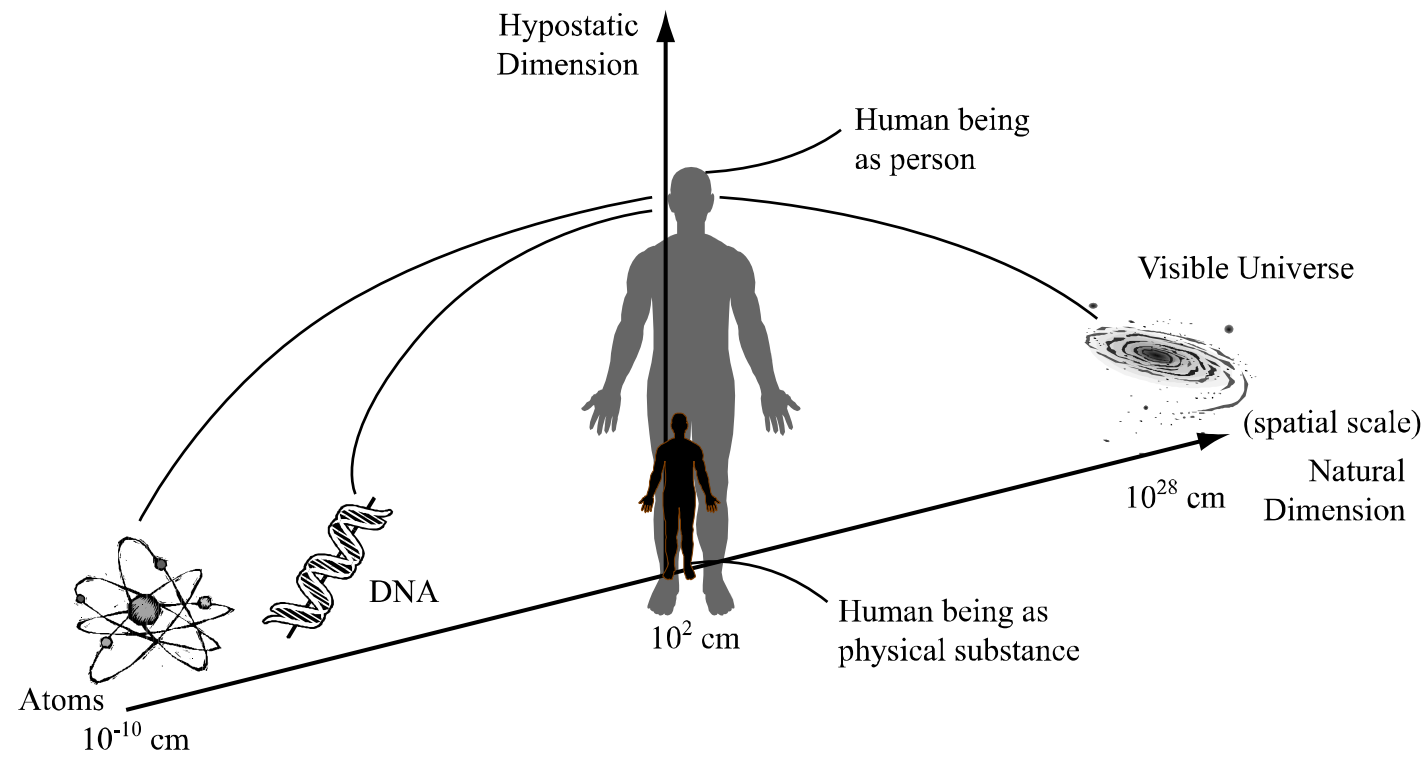

Fig. The dual position of humanity in the universe: a part of nature and the center of disclosure and manifestation

Some would say that the functions of human intellect to integrate different parts of the universe have naturally emerged, so that they constitute the part of nature, although quite different from what one means by physical nature. However, they do not explain the aspect of personhood in human existence. The personal existence means that it cannot be communicated to another person (in a contrast with the natural, let say biological factors). This literally means that the symbol of human being in the diagram as personal (large and grey) stands for the whole of mankind (in contrast to natural man (small and black)), as the community of beings with a common principle of human nature realised in different persons. One can say that the integral knowledge of the universe contains in itself an implicit premise that there is a "way" of communication with the universe, which would allow the human reason to find truth about the universe, and to share this truth among the members of the whole community. But the establishment of the "meaning" of what is contemplated by the members of the community presupposes that there is a common ground of sense and intelligibility, which is shared not only naturally (i. e. biologically on the level of the corporeal), but also personally intellectually, the very possibility of which is rooted in their common relationship to the common source of rationality in the universe.

The human ability to recapitulate in its knowledge all constituents of the universe, and to realize that human being is deeply dependent on the structural and nomistic aspects of the microworld, as well as of the mega-cosmos, makes the position of humans in the universe exceptional and unique. The recapitulation of the universe in humanity takes place not only on the natural level (which is affirmed in the anthropic arguments), but, and this is much less trivial, on the rational level; this implies indirectly that human beings are participating in outward hypostasization of their own existence by revealing the meaning of various levels of the universe. The latter is possible because human beings can use their own rationality in order to bring the undifferentiated existents in the universe to their proper, personal existing, that is as the existence through the apprehension in the persons. It is this existence of the universe through knowledge, that is in human beings, which means that the universe is articulated and constituted by human beings.

The fundamental problem, however, in asserting the idea that the universe appears to us as intelligible reality, is rooted in the origin of the intelligence of human beings and its relation to the 
intelligibility of the universe, which is discovered through the scientific quest. It follows from what we have said before that the root of human intelligence lies in the hypostatic dimension of human existence, which can be expressed in such words as the relation to the ultimate source of intelligibility which is beyond the world. This leads us to the conclusion that the act of making the universe inherent in human apprehension, means, in fact, the act of recovering of the contingent intelligibility of the Cosmos. It is clear then that for this to be possible at all one should assume that the human intelligence is somehow tuned with the intelligibility of the universe. This leads us back to the idea that the intelligence of human beings, rooted in their hypostases, and the intelligibility of the universe (which is not self-evident), which is revealed to human beings when the universe is apprehended and articulated by them, have a common root.

Conclusion. We now have come in our discussion of the place of man in the universe to the central question: why the hypostasis of human beings is an accomplished one so that they can mediate between. By posing this question we just want to express our main concern and our main argument that the mystery of the phenomenon of humanity in the universe can only partially be uncovered by the sciences in terms of the natural conditions suitable for the existence of life; the genuine problem of such a happening in the universe which we call the HumankindEvent still remains a philosophical issue, where some other, that is non-scientific sources of human experience must be invoked. This exactly points to the fact that the human hypostasis is capable of such insights and intuitions which are not accessible to the discursive thinking.

\section{REFERENCES}

1. Dyson, F.J. (1979), "Time without end: Physics and biology in an open universe", Reviews of Modern Physics, vol. 51, no. 3, p. 447. DOI: https://doi.org/10.1103/RevModPhys.51.447.

2. Barrow, J.D. and Tipler, F.J. (1986), Anthropic Cosmological Principle, Clarendon Press, Oxford, UK.

3. Krauss, L.M. and Starkman, G.D., (2000), "Life, the Universe, and Nothing: Life and Death in an Ever-Expanding Universe", The Astrophysical Journal, vol. 531, no. 1, pp. 22-30. DOI: https://doi.org/10.1086/308434.

4. Leslie, J. (1996), The End of the World, Routledge, London, UK.

5. Leslie, J. (1979), Value and Existence, Basil Blackwell, Oxford, UK.

6. Swinburne, R. (1998), "Argument from the Fine-Tuning of the Universe", Modern Cosmology and Philosophy, in Leslie, J. (ed.), Prometheus, N.Y., USA, pp. 161-163.

7. Carr, B.J. (1998), "On the Origin, Evolution and Purpose of the Physical Universe", Modern Cosmology and Philosophy, in Leslie, J. (ed.), Prometheus, N.Y., USA, pp. 152-157.

8. Leslie, J. (1998), "The Anthropic Principle Today", Modern Cosmology and Philosophy, in Leslie, J. (ed.), Prometheus, N.Y., USA, pp. 295-305.

9. Barrow, J.D. (1999), Between Inner Space and Outer Space, Oxford Univ. Press, Oxford, UK.

10. Nicolis, G. and Prigogine, I. (1989), Exploring Complexity: An Introduction, W. H. Freeman \& Co., N.Y., USA.

11. Barrow, J.D. (1995), The Artful Universe, Oxford: Clarendon, UK.

12. Penrose, R., Shimony, A., Cartwright, N., and Hawking, S. (1997), The Large, the Small and the Human Mind, Cambridge Univ. Press, Cambridge, UK.

\section{Information about the authors.}

Alexei V. Nesteruk - Dr. Sci. (Philosophy) (2019), Visiting Research Lecturer at the University of Portsmouth, Lion Gate Bld, Portsmouth, P01 3HF, UK. Associate Professor at the Inter-University Centre on Education in History and Philosophy of Science, State Marine 
Technical University, St Petersburg, 3 Lotsmanskaya str., St Petersburg 190121, Russia. The author of 114 scientific publications. Areas of expertise: cosmology, philosophy of science, the dialogue between science and theology. ORCID: https://orcid.org/0000-0001-6318-7907. E-mail: alexei.nesteruk@port.ac.uk

Aleksandr V. Soldatov - Dr. Sci. (Philosophy) (1991), Professor (1992), Head of the Department of Philosophy and Sociology, State Marine Technical University, St Petersburg, 3 Lotsmanskaya str., St Petersburg 190121, Russia. The author of 204 scientific publications. Areas of expertise: philosophy of science, philosophy of religion, sociology of science. ORCID: https://orcid.org/0000-0001-5548-1735. E-mail: soldatov2012@yandex.ru

\section{СПИСОК ЛИТЕРАТУРЫ}

1. Dyson F. J. Time without end: Physics and biology in an open universe // Reviews of Modern Physics. 1979. Vol. 51, № 3. P. 447. DOI: https://doi.org/10.1103/RevModPhys.51.447.

2. Barrow J. D., Tipler F. J. Anthropic Cosmological Principle. Oxford: Clarendon Press, 1986.

3. Krauss L. M., Starkman G. D. Life, the Universe, and Nothing: Life and Death in an Ever-Expanding Universe // The Astrophysical Journal. 2000. Vol. 531, № 1. P. 22-30. DOI: https://doi.org/10.1086/308434.

4. Leslie J. The End of the World, London: Routledge, 1996.

5. Leslie J. Value and Existence, Oxford: Basil Blackwell, 1979.

6. Swinburne R. Argument from the Fine-Tuning of the Universe // Modern Cosmology and Philosophy / in Leslie J. (ed.). N.Y.: Prometheus, 1998. P. 161-163.

7. Carr B. J. On the Origin, Evolution and Purpose of the Physical Universe, Modern Cosmology and Philosophy / in Leslie, J. (ed.), N.Y.: Prometheus, 1998. P. 152-157.

8. Leslie J. The Anthropic Principle Today // Modern Cosmology and Philosophy / in Leslie J. (ed.). N.Y.: Prometheus, 1998. P. 295-305.

9. Barrow J. D. Between Inner Space and Outer Space. Oxford: Oxford Univ. Press, 1999.

10. Nicolis G., Prigogine I. Exploring Complexity: An Introduction. N. Y.: W. H. Freeman \& Co., 1989.

11. Barrow J. D. The Artful Universe, Oxford: Clarendon, 1995.

12. The Large, the Small and the Human Mind / R. Penrose, A. Shimony, N. Cartwright, S. Hawking. Cambridge: Cambridge Univ. Press, 1997.

Информация об авторах.

Нестерук Алексей Всеволодович - доктор философских наук (2019), научный сотрудник университета Портсмута, Великобритания, Лайон Гэйт корп., Портсмут, РО1 3TR, Великобритания. Доцент межвузовского центра по образованию в области истории и философии науки при Санкт-Петербургском государственном морском техническом университете, Лоцманская ул., д. 3, Санкт-Петербург, 190121, Россия. Автор 114 научных публикаций. Сфера научных интересов: космология, философия науки, диалог между наукой и богословием. ORCID: https:/orcid.org/0000-0001-6318-7907. E-mail: alexei.nesteruk@port.ac.uk

Солдатов Александр Васильевич - доктор философских наук (1991), профессор (1992), заведующий кафедрой философии и социологии Санкт-Петербургского государственного морского технического университета, Лоцманская ул., д. 3, Санкт-Петербург, 190121, Россия. Автор 204 научных публикаций. Сфера научных интересов: философия науки, философия религии, социология науки. ORCID: https:/orcid.org/0000-0001-55481735. E-mail: soldatov2012@yandex.ru 